\title{
Research
}

Thomas Round, Carolynn Gildea, Mark Ashworth and Henrik Møller

\section{Association between use of urgent suspected cancer referral and mortality and stage at diagnosis:}

a 5-year national cohort study

\begin{abstract}
Background

There is considerable variation between GP practices in England in their use of urgent referral pathways for suspected cancer.

Aim

To determine the association between practice use of urgent referral and cancer stage at diagnosis and cancer patient mortality, for all cancers and the most common types of cancer (colorectal, lung, breast, and prostate).

\section{Design and setting}

National cohort study of 1.4 million patients diagnosed with cancer in England between 2011 and 2015.

Method

The cohort was stratified according to quintiles of urgent referral metrics. Cox proportional hazards regression was used to quantify risk of death, and logistic regression to calculate odds of late-stage (III/IV) versus early-stage (I/ II) cancers in relation to referral quintiles and cancer type.

\section{Results}

Cancer patients from the highest referring practices had a lower hazard of death (hazard ratio $[H R]=0.96 ; 95 \%$ confidence interval $[\mathrm{Cl}]=0.95$ to 0.97 ), with similar patterns for individual cancers: colorectal $(\mathrm{HR}=0.95$; $\mathrm{Cl}=0.93$ to 0.97 ); lung ( $\mathrm{HR}=0.95 ; \mathrm{Cl}=0.94$ to $0.97)$; breast ( $\mathrm{HR}=0.96 ; \mathrm{Cl}=0.93$ to 0.99$)$; and prostate $(\mathrm{HR}=0.88 ; \mathrm{Cl}=0.85$ to 0.91$)$. Similarly, for cancer patients from these practices, there were lower odds of late-stage diagnosis for individual cancer types, except for colorectal worse cancer survival rates in the UK, 1,2 with longer diagnostic intervals associated with higher mortality.3.4 Although most of those with cancer present symptomatically to primary care, 5,6 diagnosis of cancer is not straightforward. ${ }^{7.8}$ Patient-, doctor-, and system-related factors can all contribute to longer cancer diagnostic intervals. ${ }^{9-13}$ Concerns about potential diagnostic delays led to the implementation of urgent suspected cancer referral pathways, ${ }^{14,15}$ based on referral criteria defined by the National Institute for Health and Care Excellence (NICE). These pathways enable rapid access to a specialist opinion or diagnostic test (2-week wait [2WW] in England) for patients with specified symptoms. Evidence shows time to diagnosis and start of treatment is shorter for patients referred urgently, ${ }_{1}^{6,17}$ whereas longer diagnostic intervals are associated with more advanced cancers at diagnosis. ${ }^{18}$ The NICE suspected cancer referral guidelines were updated in June 2015,19 lowering the risk threshold for referral. Referrals have been increasing by approximately $10 \%$ year on year, with $>2$ million referrals in England in 2018. As a result, more patients are being diagnosed with cancer following GP referrals, with significant reductions in those diagnosed
\end{abstract} cancer

\section{Conclusion}

Higher practice use of referrals for suspected cancer is associated with lower mortality for the four most common types of cancer. A significant proportion of the observed mortality reduction is likely due to earlier stage at diagnosis, except for colorectal cancer. This adds to evidence supporting the lowering of referral thresholds and consequent increased use of urgent referral for suspected cancer.

\section{Keywords}

cancer: early diagnosis; general practice; primary care; referral and consultation.

\section{INTRODUCTION}

Late diagnosis contributes to relatively

T Round, BSc, MRCGP, GP and National Institute for Health Research doctoral research fellow, School of Population Health and Environmental Sciences, King's College London, London, and National Cancer Registration and Analysis Service, Public Health England, London. M Ashworth, DM, MRCP, FRCGP, reader, School of Population Health and Environmental Sciences; H Møller. Dr Med, professor, School of Cancer and Pharmaceutical Sciences, King's College London, London. C Gildea, MSc, senior analyst, National Cancer Registration and Analysis Service, Public Health England, London. via emergency routes. ${ }^{20}$ There is significant variation between practices in their use of urgent suspected cancer referrals, ${ }^{21-23}$ which has been a cause for concern. ${ }^{24}$ Use of urgent referrals varies by cancer site, with referral less likely for cancers characterised by non-specific presenting symptoms and patients belonging to low-cancer-incidence demographic groups. ${ }^{25}$

From financial year 2009/2010 a set of yearly suspected cancer referral metrics for every practice in England became available, produced by Public Health England (PHE). ${ }^{26}$ Previously published evidence that higher practice use of urgent referral is associated with lower cancer patient mortality ${ }^{27}$ was based on a single year (2009) cohort.

A more detailed analysis has been called for to understand variation in use of urgent referral pathways. ${ }^{14,23,28}$ This includes whether the association with cancer patient mortality can be replicated over a longer time period, is consistent across the main cancer types (colorectal, lung, breast, and prostate) - which make up approximately half of all cancer cases, and the association with stage at diagnosis. ${ }^{27}$

\section{METHOD}

In this study, cancer registration data were extracted for all patients diagnosed with cancer (ICD-10 codes C00-C97, excluding non-melanoma skin cancer [C44]] between

\section{Address for correspondence}

Thomas Round, School of Population Health and Environmental Sciences, King's College London, Addison House, Guy's Campus, London SE1 1UL, UK.

Email: thomas.roundakcl.ac.uk

Submitted: 30 October 2019; Editor's response: 7 November 2019; final acceptance: 16 December 2019.

\section{(CThe Authors}

This is the full-length article (published online $21 \mathrm{Apr} 2020$ ) of an abridged version published in print. Cite this version as: Br J Gen Pract 2020; DOI: https://doi.org/10.3399/bjgp20X709433 


\section{How this fits in}

There is considerable variation in use of urgent referral for suspected cancer between general practices. This study shows a significant association between higher practice use of urgent referral for suspected cancer and lower cancer patient mortality (2011-2015), for all cancers combined and for the most common types of cancer (colorectal, lung, breast, and prostate). A significant proportion of this reduction in mortality is likely due to earlier stage at diagnosis for all cancers, except colorectal. This study supports the observed increased use of urgent referral for suspected cancer in primary care following the updated National Institute for Health and Care Excellence guidelines.

2011 and 2015 in England from PHE's National Cancer Registration and Analysis Service (NCRAS). ${ }^{29}$ Demographic data included sex, deprivation, age at diagnosis, and vital status. For each tumour, data included diagnosis date, cancer type, stage at diagnosis, mortality, and the associated GP practice code.

These tumours were linked to GP practice metrics on urgent referrals for suspected cancer, derived from the English national Cancer Waiting Times (CWT) database. ${ }^{30}$ These metrics were based on patients with a date of first hospital appointment or treatment recorded in financial years April 2011 to March 2016, relating to approximately 6.9 million urgent referrals for suspected cancer from $>9000$ English general practices. Those with missing practice-level referral metrics were analysed separately.

Three practice-level referral metrics ${ }^{26}$ were used:

- practice referral ratio (RR) - indirectly standardised number of urgent referrals for suspected cancer, standardised according to the general practice's registered list, and age-sex distributions (mean value 1);

of urgent referral and mortality, in the presence of mediator (stage).

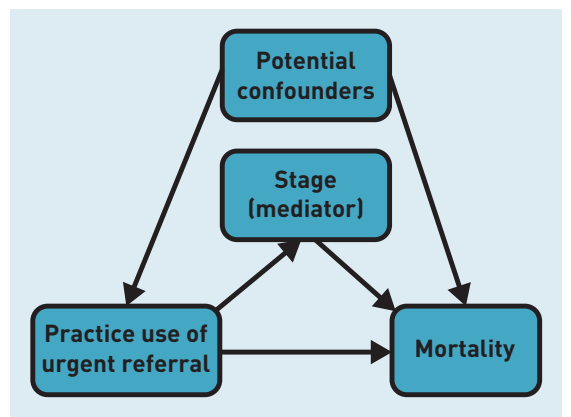

Five-year aggregated practice referral metrics were used for all cancers, and metrics were separately calculated for each of the four most common types of cancer (colorectal, lung, breast, and prostate). Similar methods were used to those previously reported, ${ }^{27,31}$ with referral metrics data analysed as categorical variables by converting rates into quintiles (that is, five groups of equal population).

Cox proportional hazards regression was used to quantify the hazard of death from any cause in relation to referral metric quintiles, including for the four main cancer types. All analyses were adjusted for the age, sex, and socioeconomic status of the individual patients. The main analysis used a 5-year time window of follow-up from diagnosis to death, ending at the earliest of 5 years or the study end date in 2017.

Logistic regression was used to calculate the odds of late-stage (III/IV) versus earlystage $(I / I I)$ cancer at diagnosis in relation to referral quintiles. A further Cox proportional hazards regression was undertaken, in which stage at diagnosis (I to IV and missing) was taken into account. This was used to determine how much of the observed changes in mortality could potentially be related to stage at diagnosis (see Figure 1 , with stage as a potential mediator between referral and mortality).

Stratified and sensitivity analyses were pursued to assess the consistency and internal validity of the findings, including a shared frailty random effects mode ${ }^{32,33}$ to accommodate the multilevel structure of data where groups of patients with cancer belong to the same general practice list. All analyses were carried out with Stata 13 and 14 .

\section{RESULTS}

Of 1469160 new cancer registrations between 2011 and 2015 (Figure 2), 57 registrations were excluded because of a negative duration of follow-up (that is, they were reported as having died before their cancer was registered). During follow-up 660606 deaths occurred (45.0\%) (for the increase in urgent referrals for suspected cancer from 2009/2010 to 2016/2017, and the impact on detection and conversion rates in England, see Supplementary Figure S1).

\section{Cohort characteristics}

Table 1 reports demographic and tumourrelated characteristics of the 1469103 cancer registrations included.

The four most common types of cancer were identified. They were: colorectal 


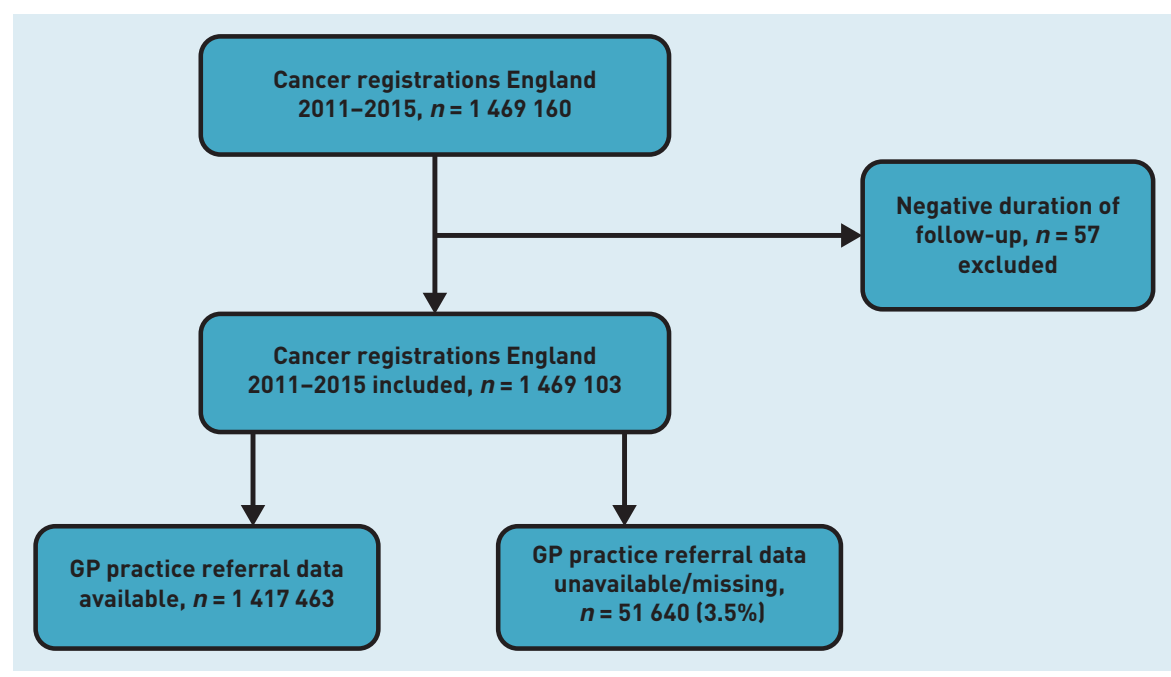

Figure 2. Flow diagram of study population with inclusions and exclusions.
( $n=173293 ; 11.8 \%)$, lung $(n=186018$; $12.7 \%)$, breast $(n=221695 ; 15.1 \%)$, and prostate $(n=196745 ; 13.4 \%)$, together accounting for $52.9 \%$ of the cohort. Onethird $(32.9 \%)$ of the cohort had missing stage data, with variation by cancer type. Separate analysis was done of the 51640 (3.5\%) cancer registrations with missing 5-year GP referral data (see Supplementary Table S1 for details). Analysis of the cohort showed that approximately $1 \%$ of cancer patients changed practice within 4 months of referral, and approximately $2.5 \%$ changed practice within 4 months of diagnosis.

\section{Distributions of referral metrics}

Table 2 reports values for the three practice referral metrics. For all cancers combined, RR medians varied from 0.67 to 1.36 , DR medians from 0.38 to 0.56 , and CR medians from 0.06 to 0.13 . Practices in the highest referral ratio quintile utilised the urgent referral pathway approximately twice as much as those in the lowest quintile.

\section{Mortality and stage analysis}

All cancers. Table 3 shows 5 -year all-cause mortality, odds of late- versus early-stage cancer at diagnosis, and mortality taking stage into account, in relation to quintiles of practice referral metrics.

Higher RR and DR quintiles were both significantly associated $(P<0.001)$ with lower hazard of death for all cancer patients (Table 3a), with four and five percentage point reductions in mortality, respectively. Moving from lowest to highest quintiles for RR and DR showed a consistent significant trend in the association with lower mortality. $\mathrm{CR}$ was not significantly associated with mortality $(P=0.872)$.
Higher practice referral (RR/DR/CR) quintiles were all significantly associated with lower odds of late-stage versus early-stage cancer at diagnosis $(P<0.001)$ (Table 3b). For the highest compared with lowest quintiles of RR and DR this equates to a two or three percentage point decrease in late-stage cancers at diagnosis.

After adjustment for stage at diagnosis, hazard ratios for the highest quintiles of $\mathrm{RR}$ and DR were attenuated (Table $3 \mathrm{c}$ compared with Table 3a), suggesting approximately half of the relative reductions in mortality for higher use of referral are potentially due to reductions in late-stage cancers at diagnosis. When stage was taken into account, higher $\mathrm{CR}$ quintiles were associated with a larger hazard of death $(H R=1.05 ; \mathrm{Cl}=1.04$ to 1.06$)$ for highest $\mathrm{CR}$ quintile.

The patterns of association were consistent for sensitivity analyses, including 1-year mortality, and from a shared frailty random effects model accounting for clustering in GP practices.

Main cancer subtypes. See Supplementary Tables S2 to S4 for a report of colorectal, lung, breast, and prostate cancer cohorts in relation to quintiles of their specific referral indices.

For the four most common cancer subtypes, similar significant associations were also found between higher RRs and lower hazard of death over 5 years ( $P$-values of $<0.001$, except for breast cancer $[P=0.005]]$.

Higher RRs were associated with lower odds of late- versus early-stage cancers at diagnosis (Supplementary Tables S2b to S5b) for all cancer types except for colorectal cancers.

When cancer stage was taken into account, hazard ratios for increasing RR were attenuated for all cancer types, except colorectal.

Table 4 summarises the percentage point difference from lowest to highest quintile of referral metrics (RR/DR/CR) for all cancers combined and most common types of cancer in relation to (a) 5-year mortality; (b) odds of late- versus earlystage cancers at diagnosis; and (c) 5-year mortality, taking stage into account. This demonstrates that a higher practice RR is significantly associated with lower cancer patient mortality and reduced late-stage diagnoses. This was found for all cancers and the most common types, except for late stage diagnosis for colorectal cancer. $\mathrm{DR}$, and particularly $\mathrm{CR}$, demonstrated less consistent associations. 
Table 1. Characteristics of the study cohort

\begin{tabular}{|c|c|c|c|c|c|c|c|c|c|c|c|c|}
\hline \multirow[b]{2}{*}{ Variable } & \multicolumn{2}{|c|}{ Colorectal } & \multicolumn{2}{|c|}{ Lung } & \multicolumn{2}{|c|}{ Breast } & \multicolumn{2}{|c|}{ Prostate } & \multicolumn{2}{|c|}{ Other } & \multicolumn{2}{|c|}{ Total } \\
\hline & $N$ & $\%$ & $N$ & $\%$ & $N$ & $\%$ & $N$ & $\%$ & $N$ & $\%$ & $N$ & $\%$ \\
\hline \multicolumn{13}{|l|}{ Year of diagnosis } \\
\hline 2011 & 34781 & 20.1 & 35849 & 19.3 & 41937 & 18.9 & 36768 & 18.7 & 131811 & 19.1 & 281146 & 19.1 \\
\hline 2012 & 35241 & 20.3 & 37250 & 20.0 & 43038 & 19.4 & 38082 & 19.4 & 135742 & 19.6 & 289353 & 19.7 \\
\hline 2013 & 34269 & 19.8 & 37410 & 20.1 & 44770 & 20.2 & 41355 & 21.0 & 140997 & 20.4 & 298801 & 20.3 \\
\hline 2014 & 34279 & 19.8 & 37868 & 20.4 & 46166 & 20.8 & 40231 & 20.4 & 141297 & 20.4 & 299841 & 20.4 \\
\hline 2015 & 34723 & 20.0 & 37641 & 20.2 & 45784 & 20.7 & 40309 & 20.5 & 141505 & 20.5 & 299962 & 20.4 \\
\hline Male & 96306 & 55.6 & 100512 & 54.0 & 0 & 0.0 & 196745 & 100.0 & 356394 & 51.6 & 749957 & 51.0 \\
\hline Female & 76987 & 44.4 & 85506 & 46.0 & 221695 & 100.0 & 0 & 0.0 & 334958 & 48.4 & 719146 & 49.0 \\
\hline \multicolumn{13}{|l|}{ Age band in years at diagnosis } \\
\hline $0-9$ & 17 & 0.0 & 11 & 0.0 & 0 & 0.0 & 6 & 0.0 & 5092 & 0.7 & 5126 & 0.3 \\
\hline $10-19$ & 382 & 0.2 & 20 & 0.0 & 15 & 0.0 & 0 & 0.0 & 4736 & 0.7 & 5153 & 0.4 \\
\hline $20-29$ & 955 & 0.6 & 168 & 0.1 & 1070 & 0.5 & 6 & 0.0 & 15357 & 2.2 & 17556 & 1.2 \\
\hline $30-39$ & 2475 & 1.4 & 603 & 0.3 & 8082 & 3.6 & 35 & 0.0 & 25238 & 3.7 & 36433 & 2.5 \\
\hline $40-49$ & 6533 & 3.8 & 4017 & 2.2 & 33845 & 15.3 & 2108 & 1.1 & 50157 & 7.3 & 96660 & 6.6 \\
\hline $50-59$ & 18881 & 10.9 & 17466 & 9.4 & 47260 & 21.3 & 20139 & 10.2 & 92720 & 13.4 & 196466 & 13.4 \\
\hline $60-69$ & 41841 & 24.1 & 49054 & 26.4 & 56719 & 25.6 & 66511 & 33.8 & 160391 & 23.2 & 374516 & 25.5 \\
\hline 70-79 & 52402 & 30.2 & 63508 & 34.1 & 39089 & 17.6 & 70260 & 35.7 & 178541 & 25.8 & 403800 & 27.5 \\
\hline 80-89 & 41661 & 24.0 & 43782 & 23.5 & 28181 & 12.7 & 32241 & 16.4 & 131084 & 19.0 & 276949 & 18.9 \\
\hline$\geq 90$ & 8146 & 4.7 & 7389 & 4.0 & 7434 & 3.4 & 5439 & 2.8 & 28036 & 4.1 & 56444 & 3.8 \\
\hline \multicolumn{13}{|l|}{ Ethnicity } \\
\hline White & 151041 & 87.2 & 162955 & 87.6 & 185967 & 83.9 & 163013 & 82.9 & 588007 & 85.1 & 1250983 & 85.2 \\
\hline Mixed & 436 & 0.3 & 395 & 0.2 & 973 & 0.4 & 648 & 0.3 & 2542 & 0.4 & 4994 & 0.3 \\
\hline Asian & 2634 & 1.5 & 2226 & 1.2 & 5788 & 2.6 & 2831 & 1.4 & 16146 & 2.3 & 29625 & 2.0 \\
\hline Black & 2090 & 1.2 & 1499 & 0.8 & 3700 & 1.7 & 5493 & 2.8 & 9681 & 1.4 & 22463 & 1.5 \\
\hline Chinese & 374 & 0.2 & 333 & 0.2 & 580 & 0.3 & 232 & 0.1 & 1459 & 0.2 & 2978 & 0.2 \\
\hline Other & 1445 & 0.8 & 1316 & 0.7 & 2312 & 1.0 & 1448 & 0.7 & 6788 & 1.0 & 13309 & 0.9 \\
\hline Unknown & 15273 & 8.8 & 17294 & 9.3 & 22375 & 10.1 & 23080 & 11.7 & 66729 & 9.7 & 144751 & 9.9 \\
\hline \multicolumn{13}{|l|}{ Deprivation quintile } \\
\hline 1 - Least deprived & 39133 & 22.6 & 27661 & 14.9 & 52523 & 23.7 & 50180 & 25.5 & 147216 & 21.3 & 316713 & 21.6 \\
\hline 2 & 39222 & 22.6 & 33855 & 18.2 & 50806 & 22.9 & 47269 & 24.0 & 151352 & 21.9 & 322504 & 22.0 \\
\hline 3 & 36421 & 21.0 & 37795 & 20.3 & 46244 & 20.9 & 40889 & 20.8 & 143742 & 20.8 & 305091 & 20.8 \\
\hline 4 & 32209 & 18.6 & 41363 & 22.2 & 40004 & 18.0 & 32820 & 16.7 & 132040 & 19.1 & 278436 & 19.0 \\
\hline 5 - Most deprived & 26308 & 15.2 & 45344 & 24.4 & 32118 & 14.5 & 25587 & 13.0 & 117002 & 16.9 & 246359 & 16.8 \\
\hline \multicolumn{13}{|l|}{ Stage at diagnosis } \\
\hline । & 23543 & 13.6 & 24724 & 13.3 & 82528 & 37.2 & 52736 & 26.8 & 133428 & 19.3 & 316959 & 21.6 \\
\hline ॥ & 35968 & 20.8 & 13127 & 7.1 & 73156 & 33.0 & 34749 & 17.7 & 55482 & 8.0 & 212482 & 14.5 \\
\hline III & 39418 & 22.7 & 34234 & 18.4 & 17429 & 7.9 & 31140 & 15.8 & 59427 & 8.6 & 181648 & 12.4 \\
\hline IV & 36214 & 20.9 & 87066 & 46.8 & 11119 & 5.0 & 31960 & 16.2 & 108842 & 15.7 & 275201 & 18.7 \\
\hline Not known & 38150 & 22.0 & 26867 & 14.4 & 37463 & 16.9 & 46160 & 23.5 & 334173 & 48.3 & 482813 & 32.9 \\
\hline \multicolumn{13}{|l|}{ 2WW referral group } \\
\hline $2 \mathrm{WW}$ & 55641 & 32.1 & 55806 & 30.0 & 98517 & 44.4 & 88507 & 45.0 & 219732 & 31.8 & 518203 & 35.3 \\
\hline Not a $2 \mathrm{WW}$ & 76961 & 44.4 & 75999 & 40.9 & 87754 & 39.6 & 60232 & 30.6 & 244595 & 35.4 & 545541 & 37.1 \\
\hline Tumour not in CWT database & 40691 & 23.5 & 54213 & 29.1 & 35424 & 16.0 & 48006 & 24.4 & 227025 & 32.8 & 405359 & 27.6 \\
\hline Total & 173293 & 11.8 & 186018 & 12.7 & 221695 & 15.1 & 196745 & 13.4 & 691352 & 47.1 & 1469103 & \\
\hline
\end{tabular}

$2 W W=$ two-wee $k$ wait. $C W T=$ Cancer Waiting Times.

\section{Missing GP referral data}

Of the total number of cases, 51640 (3.5\%) did not have GP referral data available (see Supplementary Table 1b for characteristics). Although those cohorts with missing GP referral data were of similar age distribution to the total cohort, they had lower white population $175.4 \%$ white in the missing referral data group versus $89.9 \%$ in total cohort) and showed higher rates of social deprivation $121.3 \%$ from the most deprived quintile in the missing referral data group versus $16.8 \%$ in the overall cohort). The missing referral data group also had lower rates of cancer diagnosis following urgent referral (28.2\% versus $35.3 \%)$, and higher rates of unknown stage at diagnosis $140.6 \%$ versus $32.9 \%$ ) compared with the overall cohort. Of the total, 44852 cases (86.9\%) had a registered practice code but the 
Table 2. Quintiles of practice referral metrics (RR/DR/CR) for all cancers combined and specific cancer type

\begin{tabular}{|c|c|c|c|c|c|c|c|c|c|c|c|c|c|c|c|c|}
\hline \multicolumn{2}{|c|}{ Practice referral indices } & \multicolumn{3}{|c|}{ Total (all cancers combined) } & \multicolumn{3}{|c|}{ Colorectal } & \multicolumn{3}{|c|}{ Lung } & \multicolumn{3}{|c|}{ Breast } & \multicolumn{3}{|c|}{ Prostate } \\
\hline & Quintiles & $N$ & $\%$ & Median & $N$ & $\%$ & Median & $N$ & $\%$ & Median & $N$ & $\%$ & Median & $N$ & $\%$ & Median \\
\hline \multirow[t]{6}{*}{ RR quintiles } & Q1 & 283567 & 19.3 & 0.67 & 33500 & 19.3 & 0.60 & 35748 & 19.2 & 0.52 & 43006 & 19.4 & 0.61 & 38062 & 19.3 & 0.59 \\
\hline & Q2 & 283510 & 19.3 & 0.86 & 33529 & 19.3 & 0.82 & 35790 & 19.2 & 0.77 & 42924 & 19.4 & 0.86 & 38037 & 19.3 & 0.83 \\
\hline & Q3 & 283408 & 19.3 & 1.00 & 33476 & 19.3 & 0.99 & 35708 & 19.2 & 0.98 & 42965 & 19.4 & 1.02 & 38042 & 19.3 & 1.00 \\
\hline & Q4 & 283580 & 19.3 & 1.14 & 33505 & 19.3 & 1.16 & 35755 & 19.2 & 1.25 & 42955 & 19.4 & 1.18 & 38057 & 19.3 & 1.18 \\
\hline & Q5 & 283398 & 19.3 & 1.36 & 33479 & 19.3 & 1.45 & 35736 & 19.2 & 1.81 & 42961 & 19.4 & 1.44 & 38035 & 19.3 & 1.49 \\
\hline & Missing & 51640 & 3.5 & & 5804 & 3.3 & & 7281 & 3.9 & & 6881 & 3.1 & & 6512 & 3.3 & \\
\hline \multirow[t]{6}{*}{ DR quintiles } & Q1 & 283796 & 19.3 & 0.38 & 33786 & 19.5 & 0.20 & 36576 & 19.7 & 0.17 & 43096 & 19.4 & 0.34 & 38220 & 19.4 & 0.39 \\
\hline & Q2 & 283615 & 19.3 & 0.44 & 36006 & 20.8 & 0.31 & 34949 & 18.8 & 0.32 & 43866 & 19.8 & 0.42 & 38112 & 19.4 & 0.52 \\
\hline & Q3 & 283702 & 19.3 & 0.48 & 34597 & 20.0 & 0.38 & 35821 & 19.3 & 0.40 & 42038 & 19.0 & 0.48 & 37774 & 19.2 & 0.59 \\
\hline & Q4 & 283559 & 19.3 & 0.51 & 30019 & 17.3 & 0.43 & 35669 & 19.2 & 0.47 & 43041 & 19.4 & 0.54 & 38620 & 19.6 & 0.67 \\
\hline & Q5 & 282791 & 19.3 & 0.56 & 33058 & 19.1 & 0.52 & 35697 & 19.2 & 0.57 & 42762 & 19.3 & 0.63 & 37443 & 19.0 & 0.76 \\
\hline & Missing & 51640 & 3.5 & & 5827 & 3.4 & & 7306 & 3.9 & & 6892 & 3.1 & & 6576 & 3.3 & \\
\hline \multirow[t]{6}{*}{ CR quintiles } & Q1 & 283585 & 19.3 & 0.06 & 33614 & 19.4 & 0.02 & 35777 & 19.2 & 0.09 & 43128 & 19.5 & 0.06 & 38101 & 19.4 & 0.06 \\
\hline & Q2 & 283585 & 19.3 & 0.08 & 33416 & 19.3 & 0.04 & 35797 & 19.2 & 0.17 & 43178 & 19.5 & 0.08 & 37993 & 19.3 & 0.09 \\
\hline & Q3 & 283308 & 19.3 & 0.09 & 33518 & 19.3 & 0.05 & 35669 & 19.2 & 0.22 & 42669 & 19.3 & 0.09 & 38800 & 19.7 & 0.11 \\
\hline & Q4 & 283657 & 19.3 & 0.10 & 33520 & 19.3 & 0.06 & 36086 & 19.4 & 0.27 & 42871 & 19.3 & 0.11 & 37334 & 19.0 & 0.14 \\
\hline & Q5 & 283328 & 19.3 & 0.13 & 33476 & 19.3 & 0.08 & 35382 & 19.0 & 0.33 & 42965 & 19.4 & 0.15 & 38003 & 19.3 & 0.18 \\
\hline & Missing & 51640 & 3.5 & & 5749 & 3.3 & & 7307 & 3.9 & & 6884 & 3.1 & & 6514 & 3.3 & \\
\hline
\end{tabular}

$C R=$ conversion ratio. $D R=$ detection ratio. $R R=$ referral ratio.

\section{Table 3. Analysis of mortality and stage for all cancers in relation to quintiles of referral metrics}

(a) 5-year HR-based (adjusted for age, sex, socioeconomic status)

\begin{tabular}{|c|c|c|c|c|c|c|c|c|c|c|c|}
\hline Standardised RR quintiles & HR & $\mathrm{LCl}$ & $\mathrm{UCl}$ & DR quintiles & HR & $\mathrm{LCl}$ & $\mathrm{UCl}$ & CR quintiles & HR & $\mathrm{LCl}$ & $\mathrm{UCl}$ \\
\hline 1 & 1.00 & 1 & 1.00 & 1 & 1.00 & & & & & & \\
\hline 2 & 0.98 & 0.98 & 0.99 & 2 & 0.98 & 0.97 & 0.98 & 2 & 1.02 & 1.02 & 1.03 \\
\hline 3 & 0.97 & 0.96 & 0.98 & 3 & 0.97 & 0.96 & 0.98 & 3 & 1.02 & 1.01 & 1.03 \\
\hline 4 & 0.97 & 0.96 & 0.98 & 4 & 0.96 & 0.95 & 0.97 & 4 & 1.00 & 1.00 & 1.01 \\
\hline 5 & 0.96 & 0.96 & 0.97 & 5 & 0.95 & 0.94 & 0.95 & 5 & 1.01 & 1.01 & 1.02 \\
\hline$\chi^{2}$ (one df) & 106.4 & & & $\chi^{2}$ (one df) & 187.9 & & & $\chi^{2}$ (one df) & 0.03 & & \\
\hline Pfor trend & $<0.001$ & & & Pfor trend & $<0.001$ & & & Pfor trend & 0.872 & & \\
\hline \multicolumn{12}{|c|}{ (b) Odds of stage III/IV versus I/II cancer at diagnosis (adjusted for age, sex, socioeconomic status) } \\
\hline Standardised RR quintiles & OR & $\mathrm{LCl}$ & $\mathrm{UCl}$ & DR quintiles & OR & $\mathrm{LCl}$ & $\mathrm{UCl}$ & CR quintiles & OR & $\mathrm{LCl}$ & $\mathrm{UCl}$ \\
\hline 1 & 1.00 & 1 & 1.00 & 1 & 1.00 & & & & & & \\
\hline 2 & 0.99 & 0.98 & 1.00 & 2 & 0.97 & 0.96 & 0.98 & 2 & 0.99 & 0.98 & 1.01 \\
\hline 3 & 0.97 & 0.96 & 0.98 & 3 & 0.98 & 0.96 & 0.99 & 3 & 0.98 & 0.97 & 0.99 \\
\hline 4 & 0.97 & 0.95 & 0.98 & 4 & 0.97 & 0.96 & 0.99 & 4 & 0.97 & 0.96 & 0.98 \\
\hline 5 & 0.97 & 0.95 & 0.98 & 5 & 0.96 & 0.94 & 0.97 & 5 & 0.98 & 0.97 & 1.00 \\
\hline$\chi^{2}$ (one df) & 38 & & & $\chi^{2}$ (one df) & 26.1 & & & $\chi^{2}$ (one df) & 14.7 & & \\
\hline$P$ for trend & $<0.001$ & & & Pfor trend & $<0.001$ & & & Pfor trend & $<0.001$ & & \\
\hline \multicolumn{12}{|c|}{ (c) 5-year HR (adjusted for age, sex, socioeconomic status) and adjusted for stage } \\
\hline Standardised RR quintiles & HR & $\mathrm{LCl}$ & $\mathrm{UCl}$ & DR quintiles & HR & $\mathrm{LCl}$ & $\mathrm{UCl}$ & CR quintiles & HR & $\mathrm{LCl}$ & $\mathrm{UCl}$ \\
\hline 1 & 1.00 & 1 & 1.00 & 1 & 1.00 & & & & & & \\
\hline 2 & 0.99 & 0.98 & 1.00 & 2 & 0.99 & 0.98 & 1.00 & 2 & 1.04 & 1.03 & 1.05 \\
\hline 3 & 0.99 & 0.98 & 1.00 & 3 & 0.98 & 0.98 & 0.99 & 3 & 1.05 & 1.04 & 1.06 \\
\hline 4 & 0.98 & 0.98 & 0.99 & 4 & 0.97 & 0.97 & 0.98 & 4 & 1.04 & 1.03 & 1.05 \\
\hline 5 & 0.98 & 0.97 & 0.98 & 5 & 0.97 & 0.96 & 0.97 & 5 & 1.05 & 1.04 & 1.06 \\
\hline$\chi^{2}$ (one df) & 31.9 & & & $\chi^{2}$ (one df) & 96.7 & & & $\chi^{2}$ (one df) & 100.9 & & \\
\hline Pfor trend & $<0.001$ & & & Pfor trend & $<0.001$ & & & $P$ for trend & $<0.001$ & & \\
\hline
\end{tabular}

$C l=$ confidence intervals. $C R=$ conversion ratio. $d f=$ degrees of freedom. $D R=$ detection ratio. $H R=$ hazard ratio. $L=$ lower. OR=odds ratio. $R R=$ referral ratio. $U=$ upper. 
practice did not have a full 5 years of referral data, primarily due to practice changes (for example, closure) or small list size $(<1000)$. Cases numbering 6795 (13.2\%) were without practice code, including those who were unregistered with a GP practice and those for whom NCRAS could not determine the registered practice.

Those with missing GP referral data were found to have an overall higher hazard of death over 5 years compared with those with practice referral data $(H R=1.15$; $\mathrm{Cl}=1.14$ to $1.17 ; P<0.001)$.

\section{DISCUSSION}

\section{Summary}

This analysis of $>1.4$ million patients diagnosed with cancer in England between 2011 and 2015 shows that a greater propensity to use referrals for suspected cancer was associated with lower mortality for all cancers combined and for the most common types of cancer. Significant reductions in late-stage cancers at diagnosis were found for patients from practices with higher RRs, including for the most common types of cancer, except for colorectal cancer, where there was not a significant association.

Overall, the accuracy in case selection for urgent referral (CR) was not significantly associated with mortality or stage at diagnosis. But when stage was taken into account there was an increase in mortality with the highest $\mathrm{CR}$ quintiles.

A large proportion (one-third to half) of the observed reduction in mortality with higher use of urgent referral is likely to be explained by earlier stage at diagnosis except for colorectal cancer, where lead time or other confounders may play a more important role.

Cancer patients with missing GP referral data (due to their practice not having 5 -years' referral data or not having an identifiable practice) showed significantly higher mortality.

This study has demonstrated that lower mortality and a reduction in late-stage cancers at diagnosis are associated with higher referral use. This supports the hypothesis that increased primary care use of urgent suspected cancer referrals and associated diagnostic testing may reduce late-stage diagnoses and mortality of patients with cancer. ${ }^{34,35}$

\section{Strengths and limitations}

The analysis was based on the complete national population of England, using all CWT records and population-based cancer registrations for 2011-2015. This reduces biases that can arise from the waiting times paradox, ${ }^{16,36}$ where patients with short and long times to treatment are compared. ${ }^{37}$ Also, direct comparison of urgently referred and non-referred patients is subject to selection bias and confounding by indication. ${ }^{38,39}$

As effects on mortality were estimated by time to event (death), lead time may contribute to the observed effect. Lead-time research has been focused primarily on screening,,$^{40,41}$ and in particular breast ${ }^{42,43}$ and prostate cancers, ${ }^{44}$ with relatively little mention in early symptomatic diagnosis literature. ${ }^{27,45,46}$

The most likely causes of case-mix variation between the general practices were adjusted for. ${ }^{25,47,48}$ Similar associations were found in sensitivity analyses accounting for cancer patient clustering at a practice level ${ }^{33}$ and for both 1-year and 5 -year mortality, suggesting robust results. However, as in any observational study, the possibility of confounding remains. ${ }^{38,49}$

With $>4 \%$ of patients changing practice in the study cohort, this suggests that the registered GP practice referral metrics give an accurate indication of referral patterns for the majority of patients.

At a practice level, urgent referral metrics for a single year can be based on relatively small numbers of referrals and cancer cases, meaning they exhibit year-on-year random variation, ${ }^{28}$ with differences in case-mi $x^{50}$ and in referral selection accuracy and thresholds. ${ }^{51}$ By using 5-year aggregated metrics, year-onyear random variation is reduced lalthough not completely excluded) and reliability should be improved. Even for 1-year metrics, process measures such as referral rate were shown to demonstrate acceptable reliability, ${ }^{28}$ although longer time-intervals are likely required for cancer-specific referral metrics and outcome measures such as conversion and detection rates.

Outcome measures included all-cause mortality and late versus early stage at diagnosis, and then mortality analysis taking stage into account (I to IV and missing) (see Table 4a to 4c and Supplementary Tables S2 to S5 for details) to understand the potential impact of stage on observed mortality (Figure 1). Although approximately onethird of the cohort having missing stage means the subsequent mortality analysis is potentially less robust, over time stage is increasingly better recorded within cancer registration data.

\section{Comparison with existing literature}

This study confirms the association between higher overall practice utilisation 


\section{Table 4. Percentage point difference between lowest (Q1) to highest (Q5) quintiles of referral metrics for all cancers and the most common types of cancer}

(a) 5-year mortality between Q1 to Q5

\begin{tabular}{lccc}
\hline & RR & DR & CR \\
\cline { 2 - 4 } All cancers combined & $-4 \%$ & $-5 \%$ & $1 \%^{\mathrm{a}}$ \\
Colorectal & $-5 \%$ & $-4 \%$ & $-6 \%$ \\
Lung & $-5 \%$ & $-2 \% \mathrm{a}$ & $0 \%^{\mathrm{a}}$ \\
Breast & $-4 \%$ & $3 \%^{\mathrm{a}}$ & $-2 \%^{\mathrm{a}}$ \\
Prostate & $-12 \%$ & $-4 \%$ & $-10 \%$
\end{tabular}

(b) Odds of late- versus early-stage cancers at diagnosis between Q1 to Q5

\begin{tabular}{lccc}
\hline & RR & DR & CR \\
\cline { 2 - 4 } All cancers combined & $-3 \%$ & $-4 \%$ & $-2 \%$ \\
Colorectal & $-1 \% \%^{\mathrm{a}}$ & $3 \%^{\mathrm{a}}$ & $-3 \%^{\mathrm{a}}$ \\
Lung & $-8 \%$ & $2 \%^{\mathrm{a}}$ & $0 \%^{\mathrm{a}}$ \\
Breast & $-5 \%$ & $14 \%$ & $0 \%^{\mathrm{a}}$ \\
Prostate & $-9 \%$ & $8 \%$ & $-9 \%$
\end{tabular}

(c) 5-year mortality between Q1 to Q5 taking stage into account

\begin{tabular}{lccc}
\hline & RR & DR & CR \\
\cline { 2 - 4 } All cancers combined & $-2 \%$ & $-3 \%$ & $5 \%$ \\
Colorectal & $-6 \%$ & $-4 \%$ & $-2 \%^{\mathrm{a}}$ \\
Lung & $-3 \%$ & $-2 \%^{\mathrm{a}}$ & $3 \%^{\mathrm{a}}$ \\
Breast & $0 \% \mathrm{a}$ & $3 \%^{\mathrm{a}}$ & $3 \%^{\mathrm{a}}$ \\
Prostate & $-8 \%$ & $-4 \%$ & $-4 \%$ \\
\hline
\end{tabular}

${ }^{a}$ No statistically significant trend over quintiles. $C R=$ conversion ratio. $D R=$ detection ratio. $R R=$ referral ratio research showing an association between CRs and individual GP decision making. ${ }^{55}$

Although this study focused on primary care and GP referrals for suspected cancer, there is clearly potential variation once patients are referred, including in the clinical practice of individual specialists, treatments offered, and in the wider healthcare system ${ }^{31}$ that are important to consider. ${ }^{56}$

\section{Implications for research and practice}

The significant reduction in mortality between lower and higher use of urgent referral of between four and five percentage points approaches the magnitude of known and important differences between England and comparable countries. ${ }^{57,58}$ The number of referrals did increase over the period of the study and have continued to do so, with an associated increase in the number of cancer patients diagnosed following GP referral and a decrease in the proportion of cancer patients diagnosed via emergency routes, in whom there are worse outcomes, ${ }^{39}$ from 25\% to $20 \%{ }^{20}$

Further investigations are warranted into the different scale of impact on mortality and stage at diagnosis for other specific cancer-site referral pathways, including the effect of lead time ${ }^{41,46}$ in symptomatic diagnosis - which is under-researched - and other potential mediators. In particular, there is a need to understand reasons for the observed lack of mortality reduction when stage is taken into account for colorectal cancer patients. This could include the impact of colorectal screening programmes, or, more recently, the use of Faecal Immunochemical Testing (FIT) in both screening and symptomatic presentation. Further work is needed to understand the factors associated with variation in referral including at individual GP, ${ }^{55}$ practice, ${ }^{47}$ and wider healthcare organisation levels. ${ }^{56}$

Although this study focuses on symptomatic urgent referral pathways for all cancers combined and the four most common cancer types, cancers characterised by lower-risk non-specific presenting symptoms (for example, multiple myeloma or pancreas) are likely to have multiple GP consultations prior to referral ${ }^{59}$ and pose diagnostic challenges..$^{25}$ Further development and implementation of evidence-based clinical decision tools, ${ }^{34,60}$ including addressing issues around clinician cognitive error ${ }^{61,62}$ and the potential of future novel biomarkers ${ }^{60,63}$ are needed to aid earlier cancer detection - especially for difficult-to-diagnose cancer types. 
This research adds to evidence supporting the policy of lowering referral thresholds from primarycareand subsequent increased use of suspected cancer referral pathways. ${ }^{19}$ Recommendations supporting higher $2 \mathrm{WW}$ referral rates need to be tempered by an understanding of the healthcare system. Also, the health economic implications need to be further explored, ${ }^{34}$ especially given finite staff and resources, ${ }^{64}$ and the risks of overdiagnosis. ${ }^{64,65}$ With referrals in England land other countries) increasing year on year, additional risk assessment and triage testing in primary care before referral for certain cancers, such as colorectal, ${ }^{60,63}$ may be indicated.

\section{Funding}

Thomas Round is funded by a National Institute for Health Research (NIHR) Doctoral Research Fellowship (DRF) (ref: DRF-2016-09-054) for this research project, and was previously supported by a Royal Marsden Partners (RMP) Research Fellowship. The views expressed are those of the authors and not necessarily those of the NIHR, NHS, RMP, Public Health England (PHE), or the Department of Health and Social Care.

\section{Ethical approval}

Ethics committee approval is not required for research based on routine data. Approval according to section 251 of the NHS Act 2006 applies to cancer registration and cancer intelligence in PHE.

\section{Provenance}

Freely submitted; externally peer reviewed.

\section{Competing interests}

Henrik Møller has an honorary contract with National Cancer Registration and Analysis Service (NCRAS) PHE, and Carolynn Gildea is employed by NCRAS PHE. There are no other relationships or activities that could appear to have influenced the submitted work.

\section{Acknowledgements}

This study uses data provided by patients and collected by the NHS as part of its care and support. Data for this study are based on patient-level information collected by the NHS, as part of the care and support of cancer patients. The data are collated, maintained, and quality assured by the NCRAS, which is part of PHE. The authors would like to thank their patient and public involvement steering group, which provided input to this programme of research (NIHRfunded DRF).

\section{Open access}

This article is Open Access: CC BY-NC 4.0 licence (http://creativecommons.org/ licenses/by-nc/4.0/).

\section{Discuss this article}

Contribute and read comments about this article: bjgp.org/letters 


\section{REFERENCES}

1. Department of Health. Cancer reform strategy. 2007. https://www.nhs.uk/ NHSEngland/NSF/Documents/Cancer\%20Reform\%20Strategy.pdf laccessed 2 Apr 2020).

2. Abdel-Rahman M, Stockdon D, Rachet B, et al. What if cancer survival in Britain were the same as in Europe: how many deaths are avoidable? Br J Cancer 2009; 101(S2): S115-S124.

3. Tørring ML, Frydenberg M, Hamilton W, et al. Diagnostic interval and mortality in colorectal cancer: U-shaped association demonstrated for three different datasets. J Clin Epidemiol 2012; 65(6): 669-678.

4. Tørring ML, Frydenberg M, Hansen RP, et al. Evidence of increasing mortality with longer diagnostic intervals for five common cancers: a cohort study in primary care. Eur J Cancer 2013; 49(9): 2187-2198.

5. Royal College of General Practitioners. National audit of cancer diagnosis in primary care. 2018. https://www.rcgp.org.uk/policy/rcgp-policy-areas/nationalaudit-of-cancer-diagnosis-in-primary-care.aspx laccessed 2 Apr 2020).

6. Hamilton W. Five misconceptions in cancer diagnosis. Br J Gen Pract 2009; DOI: https://doi.org/10.3399/bjgp09X420860.

7. Hamilton W, Sharp D. Diagnosis of colorectal cancer in primary care: the evidence base for guidelines. Fam Pract 2004; 21(1): 99-106.

8. Lyratzopoulos G, Wardle J, Rubin G. Rethinking diagnostic delay in cancer: how difficult is the diagnosis? BMJ 2014; 349: g7400.

9. Hansen RP, Olesen F, Sørensen HT, et al. Socioeconomic patient characteristics predict delay in cancer diagnosis: a Danish cohort study. BMC Health Serv Res 2008; 8(1): 49.

10. Scott S, Walter F, Webster A, et al. The model of pathways to treatment: conceptualization and integration with existing theory. Br J Health Psychol 2013; 18(1): 45-65.

11. Walter F, Webster A, Scott S, et al. The Andersen Model of Total Patient Delay: a systematic review of its application in cancer diagnosis. $J$ Health Serv Res Policy 2012; 17(2): 110-118.

12. Round T, Steed L, Shankleman J, et al. Primary care delays in diagnosing cancer: what is causing them and what can we do about them? J R Soc Med 2013; 106(11): 437-440.

13. Vested $\mathrm{P}$, Olesen F. Are the serious problems in cancer survival partly rooted in gatekeeper principles? An ecologic study. Br J Gen Pract 2011; DOI: https://doi. org/10.3399/bjgp11X588484.

14. Emery JD, Shaw K, Williams B, et al. The role of primary care in early detection and follow-up of cancer. Nat Rev Clin Oncol 2014; 11(1): 38-48.

15. Department of Health. HSC 2000/013: referral guidelines for suspected cancer. 2000. http://webarchive.nationalarchives.gov.uk/+/www.dh.gov.uk/ en/Publicationsandstatistics/Lettersandcirculars/Healthservicecirculars/ DH_4004320 (accessed 2 Apr 2020).

16. Neal R, Din N, Hamilton W, et al. Comparison of cancer diagnostic intervals before and after implementation of NICE guidelines: analysis of data from the UK General Practice Research Database. Br J Cancer 2013; 110(3): 584-592.

17. Olesen F, Hansen RP, Vedsted P. Delay in diagnosis: the experience in Denmark. Br J Cancer 2009; 101(Suppl 2): S5-S8.

18. Tørring ML, Murchie P, Hamilton W, et al. Evidence of advanced stage colorectal cancer with longer diagnostic intervals: a pooled analysis of seven primary care cohorts comprising 11720 patients in five countries. Br J Cancer 2017; 117(6): 888

19. National Institute for Health and Care Excellence. Suspected cancer: recognition and referral. NG12. 2015. https://www.nice.org.uk/guidance/ng12/ resources/suspected-cancer-recognition-and-referral-pdf-1837268071621 laccessed 2 Apr 2020).

20. Herbert A, Abel GA, Winters S, et al. Cancer diagnoses after emergency GP referral or $A \& E$ attendance in England: determinants and time trends in Routes to Diagnosis data, 2006-2015. Br J Gen Pract 2019; DOI: https://doi.org/10.3399/ bjgp19X705473.

21. Baughan P, Keatings J, O'Neill B. Urgent suspected cancer referrals from general practice: audit of compliance with guidelines and referral outcomes. $\mathrm{Br}$ J Gen Pract 2011; DOI: https://doi.org/10.3399/bjgp11X606591.

22. Lewis JD, Brown A, Localio AR, Schwartz JS. Initial evaluation of rectal bleeding in young persons: a cost-effectiveness analysis. Ann Intern Med 2002; 136(2): $99-110$.
23. Meechan D, Gildea C, Hollingworth L, et al. Variation in use of the 2-week referral pathway for suspected cancer: a cross-sectional analysis. Br J Gen Pract 2012; DOI: https://doi.org/10.3399/bjgp12X654551.

24. Department of Health, NHS England, Public Health England. Progress in improving cancer services and outcomes in England. 2015. https://uww.nao. org.uk/wp-content/uploads/2015/01/Progress-improving-cancer-services-andoutcomes-in-England.pdf (accessed 2 Apr 2020).

25. Zhou Y, Mendonca S, Abel G, et al. Variation in 'fast-track' referrals for suspected cancer by patient characteristic and cancer diagnosis: evidence from 670000 patients with cancers of 35 different sites. Br J Cancer 2018; 118(1): 24

26. Public Health England. Cancer services. https://fingertips.phe.org.uk/profile/ cancerservices (accessed 2 Apr 2020).

27. Møller H, Gildea C, Meechan D, et al. Use of the English urgent referral pathway for suspected cancer and mortality in patients with cancer: cohort study. BMJ 2015; 351: h5102.

28. Abel G, Saunders CL, Mendonca SC, et al. Variation and statistical reliability of publicly reported primary care diagnostic activity indicators for cancer: a crosssectional ecological study of routine data. BMJ Qual Saf2018; 27(1): 21-30.

29. Henson KE, Elliss-Brookes L, Coupland VH, et al. Data resource profile: National Cancer Registration Dataset in England. Int J Epidemiol 2019; DOI https://doi.org/10.1093/ije/dyz076.

30. NHS Digital. Cancer Waiting Times data collection. https://digital.nhs.uk/ data-and-information/data-collections-and-data-sets/data-collections/ cancerwaitingtimescwt laccessed 2 Apr 2020).

31. Møller H, Coupland VH, Tataru D, et al. Geographical variations in the use of cancer treatments are associated with survival of lung cancer patients. Thorax 2018; 73(6): 530-537.

32. Gutierrez RG. Parametric frailty and shared frailty survival models. Stata Journal 2002; 2(1): 22-44.

33. Hougaard P. Frailty models for survival data. Lifetime Data Anal 1995; 1(3): 255-273.

34. Hamilton W, Walter FM, Rubin G, Neal RD. Improving early diagnosis of symptomatic cancer. Nat Rev Clin Oncol 2016; 13(12): 740-749.

35. Hamilton W. Diagnosing symptomatic cancer in the NHS. BMJ 2015; 351: h311.

36. Tørring ML, Frydenberg M, Hansen RP, et al. Time to diagnosis and mortality in colorectal cancer: a cohort study in primary care. $\mathrm{Br}$ J Cancer 2011; 104(6): 934.

37. Di Girolamo C, Walters S, Gildea C, et al. Can we assess Cancer Waiting Time targets with cancer survival? A population-based study of individually linked data from the National Cancer Waiting Times monitoring dataset in England, 2009-2013. PloS One 2018; 13(8): e0201288.

38. Nørgaard M, Ehrenstein V, Vandenbroucke JP. Confounding in observational studies based on large health care databases: problems and potential solutions - a primer for the clinician. Clin Epidemiol 2017; 9: 185.

39. Elliss-Brookes L, McPhail S, Ives A, et al. Routes to diagnosis for cancer determining the patient journey using multiple routine data sets. $\mathrm{Br} J$ Cancer 2012; 107(8): 1220-1226.

40. Zahl P, Jørgensen KJ, Gøtzsche P. Overestimated lead times in cancer screening has led to substantial underestimation of overdiagnosis. $\mathrm{Br} J$ Cancer 2013; 109(7): 2014.

41. Duffy SW, Nagtegaal ID, Wallis M, et al. Correcting for lead time and length bias in estimating the effect of screen detection on cancer survival. Am J Epidemiol 2008; 168(1): 98-104.

42. Puliti D, Duffy S, Miccinesi G, et al. Methodology and estimate of overdiagnosis in breast cancer service screening: a review of the European studies. J Med Screen 2012; 19(S1): 42-54

43. Duffy SW, Parmar D. Overdiagnosis in breast cancer screening: the importance of length of observation period and lead time. Breast Cancer Res 2013; 15(3): R41.

44. Draisma G, Etzioni R, Tsodikov A, et al. Lead time and overdiagnosis in prostatespecific antigen screening: importance of methods and context. J Natl Cancer Inst 2009; 101(6): 374-383

45. Biswas M, Ades A, Hamilton W. Symptom lead times in lung and colorectal cancers: what are the benefits of symptom-based approaches to early diagnosis? Br J Cancer 2015; 112(2): 271.

46. Ades AE, Biswas M, Welton NJ, et al. Symptom lead time distribution in lung cancer: natural history and prospects for early diagnosis. Int J Epidemiol 2014 43(6): 1865-1873. 
47. Mendonca SC, Abel GA, Gildea C, et al. Associations between general practice characteristics with use of urgent referrals for suspected cancer and endoscopies: a cross-sectional ecological study. Fam Pract 2018; 36(5): 573-580.

48. Murchie P, Chowdhury A, Smith S, et al. General practice performance in referral for suspected cancer: influence of number of cases and case-mix on publicly reported data. Br J Cancer 2015; 112(11): 1791-1798.

49. Bosco JL, Silliman RA, Thwin SS, et al. A most stubborn bias: no adjustment method fully resolves confounding by indication in observational studies. J Clin Epidemiol 2010; 63(1): 64-74

50. Murchie P, Chowdhury A, Smith S, et al. General practice performance in referral for suspected cancer: influence of number of cases and case-mix on publicly reported data. Br J Cancer 2015; 112(11): 1791.

51. Burton CD, McLernon DJ, Lee AJ, et al. Distinguishing variation in referral accuracy from referral threshold: analysis of a national dataset of referrals for suspected cancer. BMJ Open 2017; 7(8): e016439.

52. Shawihdi M, Thompson E, Kapoor N, et al. Variation in gastroscopy rate in English general practice and outcome for oesophagogastric cancer: retrospective analysis of Hospital Episode Statistics. Gut 2014; 63(2): 250-261.

53. Maclean R, Jeffreys M, Ives $A$, et al. Primary care characteristics and stage of cancer at diagnosis using data from the National Cancer Registration Service Quality Outcomes Framework and general practice information. BMC Cancer 2015; 15(1): 1

54. Lyratzopoulos G, Mendonca SC, Gildea C, et al. Associations between diagnostic activity and measures of patient experience in primary care: a cross-sectional ecological study of English general practices. Br J Gen Pract 2018; DOI: https:// doi.org/10.3399/bjgp17X694097.

55. Kostopoulou O, Nurek M, Cantarella S, et al. Referral decision making of general practitioners: a signal detection study. Med Decis Making 2019; 39(1): 21-31.
56. Burton C, O'Neill L, Oliver P, Murchie P. Contribution of primary care organisation and specialist care provider to variation in GP referrals for suspected cancer: ecological analysis of national data. BMJ Qual Saf 2019: DOI: 10.1136/bmjqs-2019-009469.

57. Morris EJ, Sandin F, Lambert PC, et al. A population-based comparison of the survival of patients with colorectal cancer in England, Norway and Sweden between 1996 and 2004. Gut 2011; 60(8): 1087-1093.

58. Coleman M, Forman D, Bryant $\mathrm{H}$, et al. Cancer survival in Australia, Canada, Denmark, Norway, Sweden, and the UK, 1995-2007 (the International Cancer Benchmarking Partnership): an analysis of population-based cancer registry data. Lancet 2011; 377(9760): 127-138.

59. Lyratzopoulos G, Neal RD, Barbiere JM, et al. Variation in number of general practitioner consultations before hospital referral for cancer: findings from the 2010 National Cancer Patient Experience Survey in England. Lancet Oncol 2012; 13(4): 353-365.

60. Rubin $\mathrm{G}$, Berendsen $\mathrm{A}$, Crawford SM, et al. The expanding role of primary care in cancer control. Lancet Oncol 2015; 16(12): 1231-1272.

61. Kostopoulou O, Rosen A, Round T, et al. Early diagnostic suggestions improve accuracy of GPs: a randomised controlled trial using computer-simulated patients. Br J Gen Pract 2015; DOI: https://doi.org/10.3399/bjgp15X683161.

62. Kostopoulou $\mathrm{O}$, Sirota M, Round $\mathrm{T}$, et al. The role of physicians' first impressions in the diagnosis of possible cancers without alarm symptoms. Med Decis Making 2017; 37(1): 9-16

63. Rubin $G$, Walter F, Emery J, et al. Reimagining the diagnostic pathway for gastrointestinal cancer. Nat Rev Gastroenterol Hepatol 2018; 15(3): 181

64. Round T. Primary care and cancer: facing the challenge of early diagnosis and survivorship. Eur J Cancer Care 2017; 26(3): e12703.

65. Nicholson B. Detecting cancer in primary care: where does early diagnosis stop and overdiagnosis begin? Eur J Cancer Care 2017; 26(3): e12692. 